ABDIMAS: Jurnal Pengabdian Masyarakat Universitas Merdeka Malang
Vol.6(1) February 2021, 82-89
L-ISSN: 2721-138x e-ISSN: 2548-7159
Uttp://jurnal.unmer.ac.id/index.php/jpkm

\title{
Pendampingan dan Penerapan Teknologi Tepat Guna untuk Peningkatan Produktivitas Usaha Mebel Kota Kupang
}

\author{
Nursalim', Agusthinus S. Sampeallo', Abdul Wahid², Nixson J. Meok ${ }^{3}$ \\ ${ }^{1}$ Departemen Teknik Elektro, ${ }^{2}$ Departemen Fisika Fakultas Sains dan Teknik, ${ }^{3}$ Departemen Pendidikan Teknik Elektro, \\ Fakultas Keguruan dan Ilmu Pendidikan, Universitas Nusa Cendana \\ Jl. Adi Sucipto Penfui No.85001, Kupang, Nusa Tenggara Timur, Indonesia
}

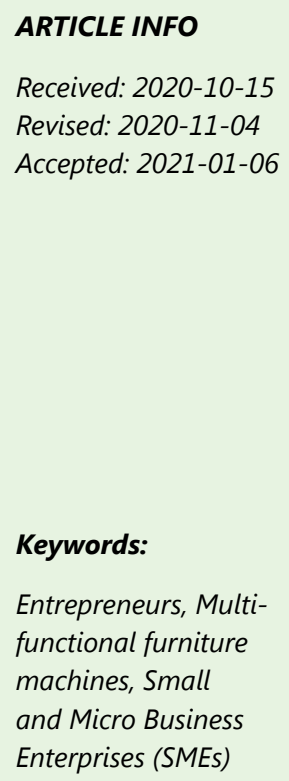

\section{ABSTRACT}

The macroeconomic growth in East Nusa Tenggara (NTT) has shown changes for the better in var-ious fields. This improving economic growth has also had a positive impact on the retail business sector. This is indicated by the increasing interest of the people of Kupang city towards wooden furniture. However, the increasing public interest in furniture is a challenge for furniture entrepreneurs to be able to meet these needs. UD. Gusti Karya is a micro business unit that produces furniture in the city of Kupang. UD. Gusti Karya has started its activities since 1997, but until now the turnover generated has continued to decline due to the limited functionality of the furniture machines used. This activity is part of the PPPUD Program in partnership with UD. Gusti Karya. This activity aims to provide solutions to problems that are being faced by UD. Gusti Karya, which is a micro business unit that produces furniture in the city of Kupang. The solution given is related to productivity problems, by providing assistance and the application of more modern multi-functional furniture machines. Because according to partners, so far, they still use manual equipment more, so it is necessary to implement machines that have more modern technology than those currently available. The output that was achieved from the implementation of this program was an increase in productivity which resulted in an increase in partner turnover by $78.9 \%$ from the previous one.

(C) 2021 Published by University of Merdeka Malang.

This is an open access article distributed under the CC BY-SA 4.0 license

(https://creativecommons.org/licenses/by-sa/4.0/)

How to cite: Nursalim, Sampeallo, A. S., Wahid, A., \& Meok, N. J. (2021). Pendampingan dan Penerapan Teknologi Tepat Guna untuk Peningkatan Produktivitas Usaha Mebel Kota Kupang. Abdimas: Jurnal Pengabdian Masyarakat Universitas Merdeka Malang, 6(1), 82-89. https://doi.org/10.26905/abdimas.v6i1.4943

\section{PENDAHULUAN}

Pertumbuhan ekonomi makro di Nusa Tenggara Timur (NTT) sudah memperlihatkan perubahanperubahan ke arah yang lebih baik dalam bermacam bidang. Namun demikian, pembangunan wilayah ini masih memerlukan kerja keras dari berbagai kalangan khususnya di bidang Usaha Mikro Kecil Menengah (UMKM), sehingga usaha ini dapat meningkatkan persaingan secara luas khususnya untuk menghadapi perdagangan bebas Masyarakat Ekonomi ASEAN (MEA) yang telah diberlakukan mulai di tahun 2016. MEA sendiri adalah merupakan sebuah peluang sekaligus tantangan. Karena dengan 
adanya MEA, barang dan jasa, investasi, serta tenaga kerja terampil akan bebas bergerak dan mengalir diantara negara-negara ASEAN, begitupun dengan pembebasan tarif bea masuk, kemudahan perizinan, dan pembebasan visa kerja ( Windhyastiti et al., 2019; Usman, 2016;). Namun dengan demikian, MEA juga dapat membuka pangsa yang seluas-luasnya bagi produsen. Sehingga MEA juga diyakini dapat membuat warga untuk dapat meningkatkan kualitas hidupnya, baik kualitas personal maupun produkproduk yang dimilikinya agar mampu bersaing dengan bangsa lain (Nursalim et al., 2019).

Menurut Data BPS, kayu jati adalah merupakan jenis hasil hutan terbanyak kedua di Provinsi Nusa Tenggara Timur (NTT) setelah jenis hasil hutan rimba campuran. Data statistik menyebutkan bahwa produksi kayu jati pada tahun 2017 mencapai 1.986.78 m3 (Sedeh, 2017). Memang jika dilihat dari kontribusi subsektor kehutanan, hasil hutan NTT memang masih relatif kecil terhadap PDRB yaitu sebesar 0.15 persen. Namun seiring perkembangan dari UMKM usaha mebeler, maka budidaya hutan terutama jenis pohon jati putih semakin digemari oleh masyarakat karena omzet yang di hasilkan sangat menjanjikan (Pos Kupang, 2011). Jenis kayu jati NTT ini selain disukai oleh masyarakat NTT, juga disukai oleh masyarakat mancanegara khususnya masyarakat Timor Leste. Hal tersebut dibuktikan oleh banyaknya permintaan kayu ke negara tersebut di tahun 2020 ini (Ferdianto, 2020). Tentu saja hal tersebut sangat membuka peluang bagi pengusaha, khususnya pengusaha mebel di NTT.

Bahan mebel dari kayu jati saat ini memang semakin diminati oleh warga Kota Kupang, karena selain dapat dibuat sesuai selera konsumen, kayu jati juga merupakan merupakan jenis kayu yang kuat dan tahan terhadap jamur, rayap, dan serangga (Hunggurami et al. 2016; Tanubrata, 2015; Wahyudi et al., 2014; Basri \& Wahyudi, 2013;). Keistimewaan inilah yang membuat kayu jati banyak dijadikan sebagai bahan baku utama pembuatan mebel. Hal tersebut kemudian dipertegas oleh bapak Gabriel D.H Lopo selaku pemilik UD. Gusti karya, yang merupakan mitra UMKM pelaksana Program Pengembangan Produk Unggulan Daerah (PPPUD) saat ini. Menurut mitra, bahwa sejak dia mendirikan usaha mebel dari Tahun 1997 sampai masa pandemi Covid-19 ini belum pernah sepi dari orderan pelanggan. Tentu itu, saja hal tersebut disebabkan oleh semakin tingginya minat masyarakat Kota Kupang terhadap mebel berbahan kayu jati ini. Bahkan menurut mitra, hasil kerajinan mebel kayu jati yang dihasilkannya, bukan hanya dikenal di sekitar Kota Kupang, namun juga telah dikenal sampai keluar Kota Kupang, khususnya di Kota Maumere yang ada di Pulau Flores.

Walaupun produknya telah terkenal, namun usaha mitra belum dapat berkembang. Menurut mitra, salah satu faktor penyebabnya adalah karena peralatan yang digunakan sudah terbelakang.

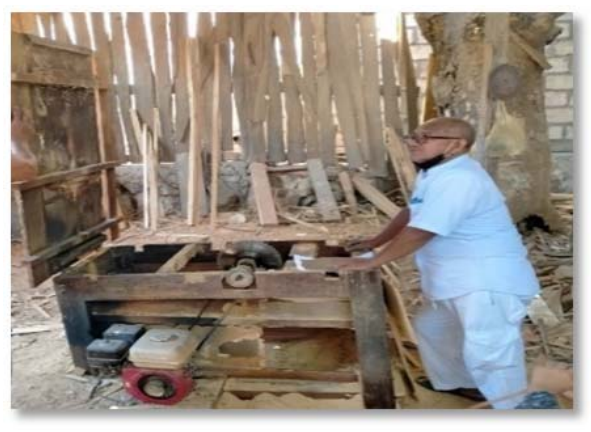

Gambar 1. Mesin produksi kayu UD. Gusti Karya 
ABDIMAS: Jurnal Pengabdian Masyarakat Universitas Merdeka Malang Volume 6, No. 1, February 2021: 82-89

Menurutnya, sejak memulai usaha di tahun 1997, belum pernah mengganti atau memperbaharui mesin-mesin produksi tersebut karena disebabkan adanya keterbatasan modal usaha yang dimilikinya. Akibatnya, beberapa tahun terakhir omzet yang didapatkan dari usaha ini semakin menurun. Data ini digambarkan pada grafik penjualan mitra pada tahun 2018 - 2019 yang dapat dilihat pada Gambar 2 .

Menurut mitra, turunnya omzet ini disebabkan karena lambannya proses produksi yang diakibatkan oleh keterbatasan mesin mebeler yang dimilikinya. Sebagai asumsi, untuk menyelesaikan produk lemari 2 pintu, mitra membutuhkan waktu \pm 8 hari.

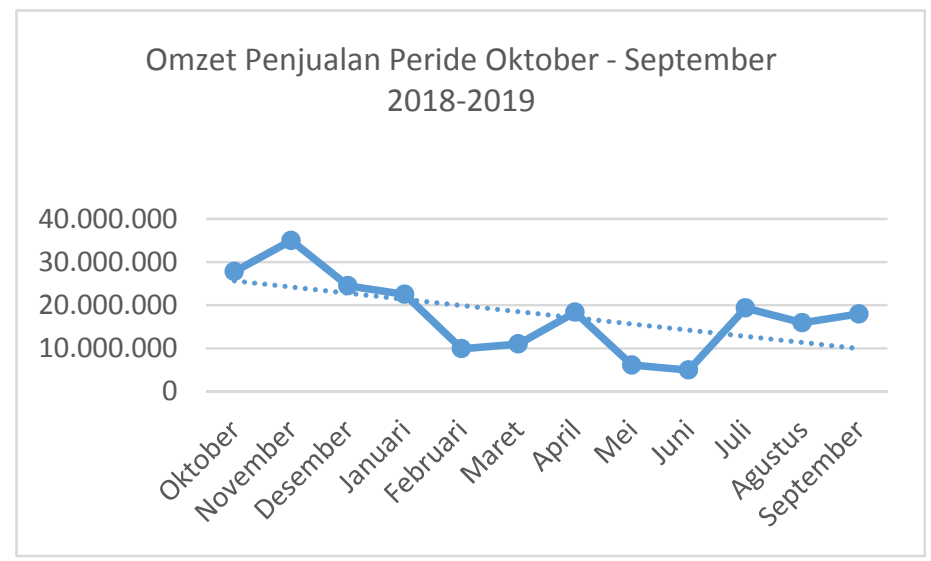

Gambar 2. Grafik omzet penjualan UD. Gusti Karya

Program PPPUD ini bertujuan untuk memberikan solusi terhadap permasalahan yang sedang dihadapi oleh mitra yang terkait dengan masalah percepatan proses produksi mebeler dengan cara, melakukan pendampingan dan menerapkan mesin-mesin mebeler multi fungsi yang lebih modern, sehingga produktivitas dapat meningkat yang berdampak terhadap peningkatan omzet.

Mesin mebeler yang akan diterapkan dalam kegiatan ini adalah merupakan penggabungan beberapa mesin mebeler seperti, mesin planner, mesin bor, dan mesin circular saw. Mesin-mesin tersebut didesain sedemikian rupa sehingga dapat melakukan hingga 7 (tujuh) jenis pekerjaan kayu yang berbeda. Adapun maksud penggunaan mesin mebeler multi fungsi tersebut yaitu untuk mengoptimalkan proses produksi, sehingga produktivitas dan omzet penjualan dapat meningkat.

\section{METODE}

Kegiatan yang dilakukan pada UD. Gusti Karya disesuaikan dengan pemecahan permasalahan yang telah diusulkan sebelumnya. Untuk memecahkan permasalahan kapasitas produksi,maka pengusul bersama mitra melakukan metode pelaksanaan sebagai berikut: (1) Metode diseminasi pemanfaatan teknologi tepat guna. Pada metode ini, mitra dan tim pelaksana melakukan diskusi untuk menggali informasi tentang permasalahan-permasalahan yang sedang dihadapi oleh mitra. Informasi tersebut kemudian dijadikan sebagai acuan untuk menentukan jenis mesin yang akan diterapkan pada mitra; (2) Metode pengadaan dan penerapan alat dengan teknologi tepat guna. Melalui metode tersebut 
disepakati bahwa alat yang akan diadakan pada tahun pertama kegiatan PPPUD adalah mesin multi fungsi yang terdiri dari mesin planner, bor, dan circular saw untuk mengoptimalkan proses produksi; (3) Metode pendampingan dan monitoring. Kegiatan pendampingan ini dilakukan sebagai bentuk layanan yang diberikan ke mitra pelaku usaha secara intensif dan berkelanjutan untuk mendapatkan informasi tentang permasalahan penggunaan mesin maupun teknik penggunaan mesin yang efektif dan efisien. Adapun tata cara konsultasi, dilakukan melalui tatap muka maupun melalui telepon, sedangkan dalam pendampingan, yaitu mendampingi pelaku usaha secara langsung bersama dengan anggota tim yang terkait. Sedangkan kegiatan monitoring dan evaluasi (monev), dilakukan dengan tujuan untuk mengetahui perkembangan dan kemajuan, serta mengidentifikasi permasalahan mitra guna melakukan upaya pemecahan masalah yang dihadapinya. Monitoring ini dilakukan dengan cara menggali untuk mendapatkan informasi secara reguler berdasarkan indikator tertentu, dengan maksud mengetahui apakah kegiatan yang sedang berlangsung sesuai dengan perencanaan dan prosedur yang telah disepakati.

\section{HASIL DAN PEMBAHASAN}

Hasil luaran yang diharapkan oleh kegiatan PPPUD ini adalah diperolehnya peningkatan produksi pada UD. Gusti Karya selaku mitra PPPUD. Oleh karenanya fasilitasi mesin mebeler multi fungsi menjadi salah satu solusi tepat guna pada proses pembuatan mebeler terutama dalam proses pembelahan, pemotongan, pengeboran dan penyerutan kayu, sehingga produktivitas mebeler dapat lebih optimal karena dikerjakan pada mesin yang lebih modern. Adapun urutan pelaksanaan kegiatan adalah sebagai berikut:

\section{Penempatan dan pengaturan tata letak mesin mebeler}

Kegiatan ini bertujuan untuk menentukan tata letak mesin mebeler, sehingga didapatkan posisi dan arah yang tepat bagi pekerja untuk melakukan pekerjaannya secara leluasa, aman dan nyaman. Setelah mendapatkan posisi yang tepat, kegiatan selanjutnya adalah meratakan lantai dengan campuran pasir dan semen, sehingga posisi mesin dapat menjadi rata dan kokoh. Hasil kegiatan dapat dilihat pada Gambar 3.
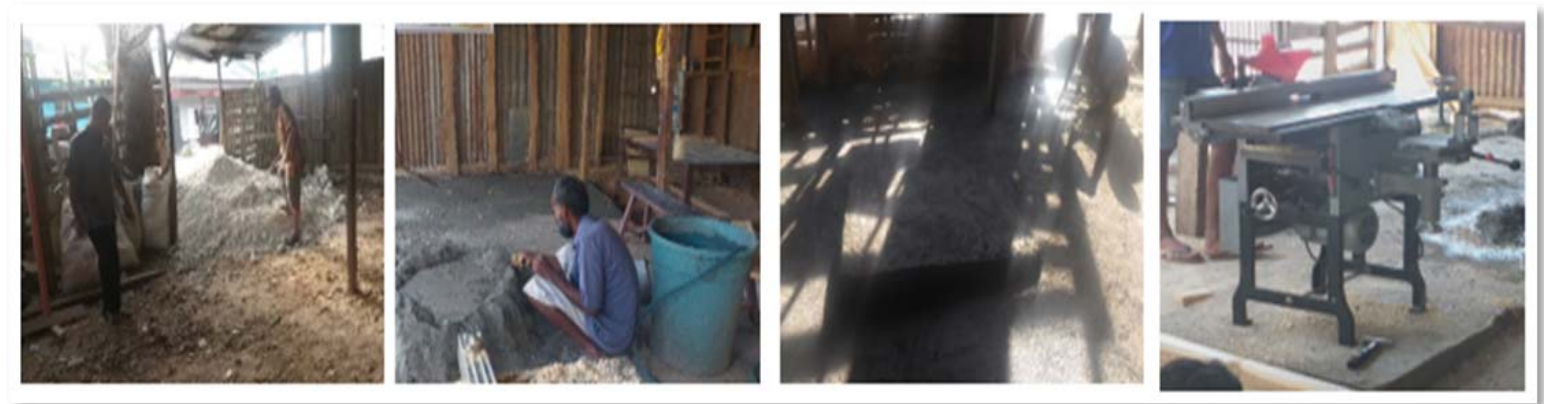

Gambar 3. Kegiatan penentuan tata letak mesin mebeler multi fungsi 
ABDIMAS: Jurnal Pengabdian Masyarakat Universitas Merdeka Malang

Volume 6, No. 1, February 2021: 82-89

\section{Perakitan Mesin Mebeler Multi Fungsi}

Setelah penentuan penentuan tata letak dan pembuatan lantai dasar mesin mebeler selesai, kegiatan berikutnya adalah perakitan mesin mebeler dengan ketelitian dan detail yang cukup tinggi. Hal ini bertujuan agar mesin dapat bekerja secara maksimal. Perakitan diawali dengan merakit kaki mesin di tempat yang telah ditentukan sebelumnya. Perakitan ini melibatkan semua tim pengabdi termasuk narasumber yang telah berpengalaman dibidangnya, sehingga perakitan mesin ini, dapat berjalan lancar serta dapat berfungsi sesuai dengan yang diharapkan. Adapun gambar perakitan mesin produksi ini diperlihatkan pada Gambar 4.
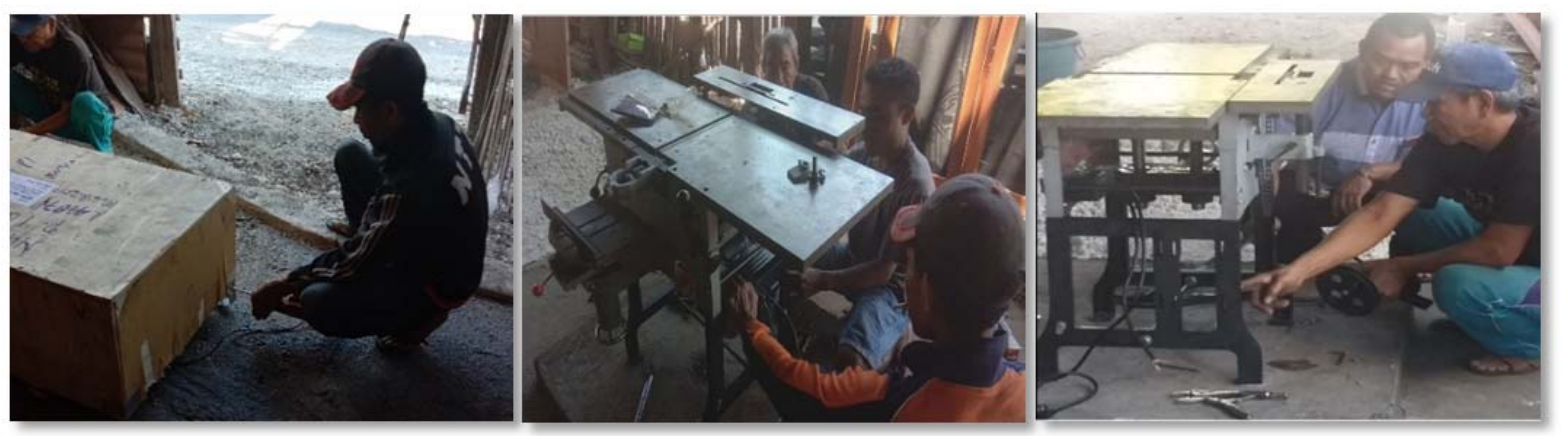

Gambar 4. Perakitan mesin mebeler multi fungsi

\section{Demonstrasi dan pengujian mesin mebeler multi fungsi}

Kegiatan ini dilakukan untuk menguji dan melihat performa mesin, sekaligus untuk memastikan bahwa mesin sudah terpasang sesuai dengan desain pabriknya. Pengujian dilakukan dengan menggunakan berbagai jenis kayu dan ukuran. Pengujian ini dilakukan untuk mengetahui apakah mesin telah bekerja sesuai dengan spesifikasi yang diharapkan. Adapun gambar dapat dilihat pada Gambar 5 .
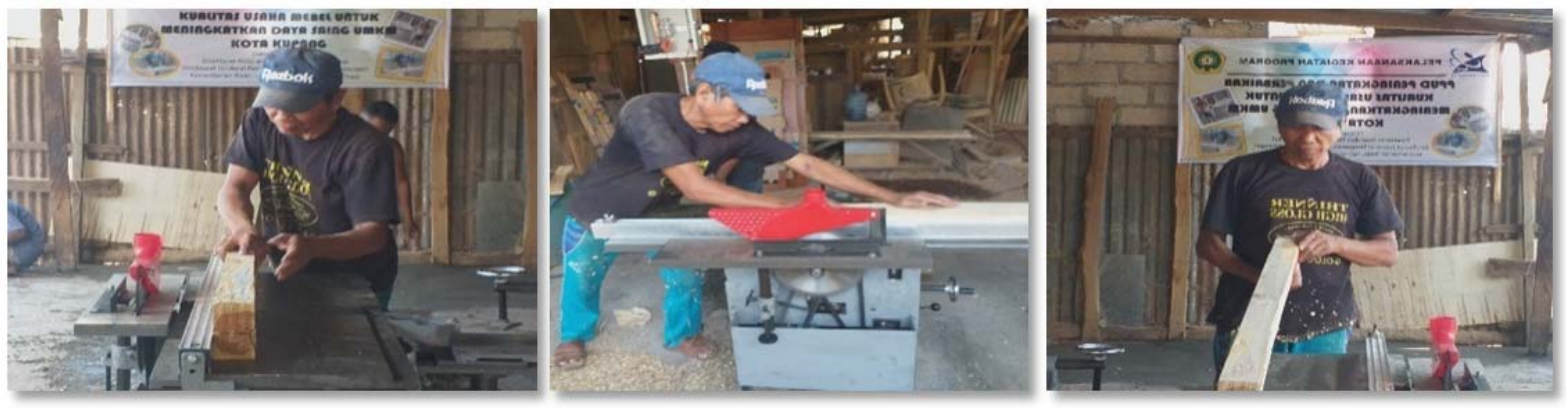

Gambar 5. Pengujian mesin mebeler multi fungsi 


\section{Pendampingan dan evaluasi}

Pendampingan dan evaluasi dilakukan secara bersama-sama dengan menitikberatkan pada teknik penggunaan mesin yang efektif dan efisien untuk meningkatkan produksi mebel. Sedangkan evaluasi dilakukan dengan membandingkan kinerja mesin yang dimiliki oleh mitra terhadap mesin yang diterapkan pada kegiatan ini. Evaluasi ini mengambil sampel dari proses pengerjaan lemari 2 pintu, karena proses ini dianggap membutuhkan banyak waktu yakni sekitar \pm 8 hari. Hasil pendampingan dan evaluasi menunjukkan bahwa, dengan penggunaan dan penerapan teknologi mesin multi fungsi, dapat mempercepat proses produksi dengan mempersingkat waktu pengerjaan lemari 2 pintu menjadi 5 hari atau lebih cepat 3 hari dibanding sebelumnya. Hasil yang dicapai oleh kegiatan ini adalah selain meningkatkan jumlah produktivitas, juga menurunkan biaya produksi, sehingga akan berdampak pada peningkatan omzet penjualan mitra.
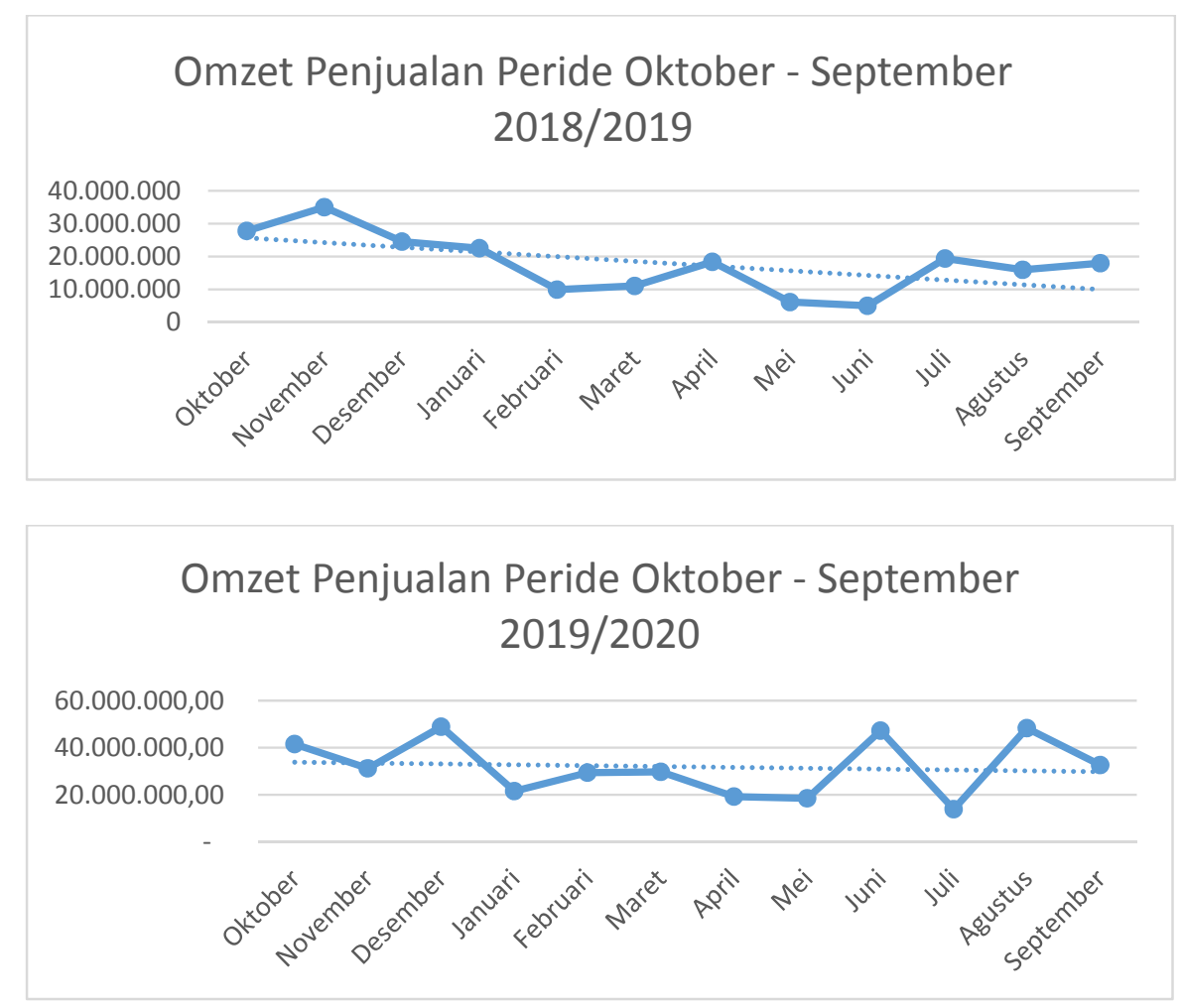

Gambar 6. Omzet penjualan UD. Gusti Karya sebelum dan sesudah kegiatan

Berdasarkan gambar 6 diketahui bahwa setelah adanya kegiatan ini ini, omzet mitra dapat meningkat dibanding sebelumnya. Gambar 6 tersebut memperlihatkan bahwa sebelum adanya kegiatan ini, omzet mitra adalah rata-rata senilai Rp. 17,775,000.00, dan setelah adanya kegiatan ini, omzet ratarata mitra adalah Rp. 31,815,416.67. 
ABDIMAS: Jurnal Pengabdian Masyarakat Universitas Merdeka Malang Volume 6, No. 1, February 2021: 82-89

\section{SIMPULAN DAN SARAN}

\section{Simpulan}

Hasil evaluasi memperlihatkan adanya peningkatan produktivitas yang berdampak terhadap peningkatan omzet mitra. Hasil pendampingan dan evaluasi menunjukkan bahwa penggunaan dan penerapan teknologi mesin multi fungsi, dapat mempercepat proses produksi dengan mempersingkat waktu pengerjaan lemari 2 pintu menjadi 5 hari atau lebih cepat 3 hari dibanding sebelumnya. Kegiatan ini meningkatkan omzet mitra dari Rp. 17,775,000.00 menjadi Rp. 31,815,416.67, atau terjadi peeningkatan omzet sebesar $78,9 \%$ dari sebelumnya. Kegiatan ini telah berjalan sesuai dengan yang direncanakan yaitu tercapainya peningkatan produktivitas mitra yang berdampak pada peningkatan omzet mitra.

\section{Ucapan Terima Kasih}

Tim Pelaksana mengucapkan terima kasih kepada DRPM DIKTI (RISTEK-BRIN) yang telah memberikan dana sehingga pelaksanaan kegiatan ini dapat berjalan lancar sesuai dengan yang direncanakan. Selanjutnya tim Pelaksana juga mengucapkan terima kasih kepada Universitas Nusa Cendana khususnya Lembaga Penelitian dan Pengabdian Masyarakat (LP2M), yang senantiasa memantau dan memberi motivasi sehingga kegiatan ini dapat berjalan seperti yang diharapkan.

\section{DAFTAR PUSTAKA}

Basri, E., \& Wahyudi, I. (2013). Sifat dasar kayu jati plus perhutani dari berbagai umur dan kaitannya dengan sifat dan kualitas pengeringan. Jurnal Penelitian Hasil Hutan, 31(2), 93-102. https://doi.org/10.20886/jphh.2013.31.2.93-102

Ferdianto, A. (2020). Permintaan ekspor kayu jati dari NTT meningkat di masa pandemi. Diakses pada 13 Oktober 2020, dari https://pertanian.sariagri.id/60686/permintaan-ekspor-kayu-jati-darintt-meningkat-di-masa-pandemi

Hunggurami, E., Utomo, S., \& Messakh, B. Y. (2016). Identifikasi kuat acuan terhadap jenis kayu yang diperdagangkan di Kota Kupang Berdasarkan SNI 7973: 2013. Jurnal Teknik Sipil, 5(2), 175184.

Nursalim, N., Sampeallo, A. S., Wahid, A., \& Meok, N. J. (2019). Upaya peningkatan produksi mebel pada UMKM Kota Kupang berbasis teknologi tepat guna. Dinamisia: Jurnal Pengabdian kepada Masyarakat, 3(2), 258-265. https://doi.org/10.31849/dinamisia.v3i2.3681

Pos Kupang (2011, 23 Juni). Mebel kayu jati diminati warga Kupang. Diakses dari https://kupang.tribunnews.com/2011/06/23/mebel-kayu-jati-diminati-warga-kupang?page=2

Sedeh, Z. I. P. (2017). Statistik Pertanian Provinsi Nusa Tenggara Timur 2017. Nusa Tenggara Timur: Badan Pusat Statistik Provinsi Nusa Tenggara Timur.

Tanubrata, M. (2015). Bahan-bahan konstruksi dalam konteks teknik sipil. Jurnal Teknik Sipil, 11(2), 132-154. https://doi.org/10.28932/jts.v11i2.1407 
Pendampingan dan Penerapan Teknologi Tepat Guna untuk Peningkatan Produktivitas Usaha Mebel Kota Kupang Nursalim, Agusthinus S. Sampeallo, Abdul Wahid, Nixson J. Meok

Usman, F. (2016). Masyarakat Ekonomi ASEAN (MEA) dan daya saing investasi Indonesia. Jurnal Lingkar Widyaiswara, 3(1), 33-36.

Wahyudi, I., Priadi, T., \& Rahayu, I. S. (2014). Karakteristik dan sifat-sifat dasar kayu jati unggul umur 4 dan 5 tahun asal Jawa Barat. Jurnal Ilmu Pertanian Indonesia, 19(1), 50-56.

Windhyastiti, I., Hidayatullah, S., \& Khouroh, U. (2019). How to increase city investment attraction. International Journal of Scientific \& Technology Research, 8(09), 1070-1073. 